\title{
Projections of twenty-first century climate over Europe
}

\author{
F. Giorgi and E. Coppola \\ Abdus Salam International Centre for Theoretical Physics, Trieste, Italy
}

\begin{abstract}
We present an assessment of climate change projections over the European region for the $21^{\text {st }}$ century from the ensembles of CMIP3 global model experiments and PRUDENCE regional climate model experiments. The A2, A1B, and B1 IPCC emission scenarios are considered. A brief review is also presented of the literature available on future European climate projections. In all emission scenarios the European region shows maximum warming of up to several degrees $\mathrm{C}$ over the Mediterranean region in summer and over northeastern Europe in winter. The precipitation change signal shows a north-south dipolar structure, with increasing precipitation over Northern Europe and decreasing over southern Europe. This structure migrates northward from the winter to the summer and is tied to the north-south motion of an increasing anticyclonic circulation cell over the North Atlantic-European sector. Temperature interannual variability decreases in winter over central and northern Europe and increases in summer throughout Europe. Precipitation interannual variability shows a predominant increase, most pronounced in summer. The seasonal temperature anomaly probability density functions (PDFs) show a shift and a widening and flattening in future climate conditions, especially in summer, which is indicative of pronounced increases of extreme hot seasons. The seasonal precipitation anomaly PDFs show pronounced changes over Southern Europe in summer, with a strong increase of very dry seasons. In general, the magnitude of future climate change increases with the greenhouse gas forcing. A broad consensus is found between the projections obtained with the CMIP3 and PRUDENCE ensembles, as well as between the present analysis and previous generations of model projections. The climate change signal over Europe exhibits a consistent latitudinal and seasonal evolution identified as the European Climate change Oscillation (ECO) by Giorgi and Coppola [1]. The changes of temperature and precipitation over Europe are pronounced, making this region highly vulnerable to global warming.
\end{abstract}

\section{Introduction}

The European region has been identified as being particularly sensitive to projected $21^{\text {st }}$ century global warming [2]. In fact, different generations of model projections indicate that, under the influence of increased concentrations of greenhouse gases (GHG), Europe would warm much more than the global average and would undergo large changes in precipitation [3-6]. In other words, Europe can be considered as one of the most prominent $21^{\text {st }}$ century climate change hot-spots [2] and is thus potentially highly vulnerable to global warming.

In the last decades a multitude of studies have been carried out on $21^{\text {st }}$ century climate change over Europe as part of both, various multi-national projects sponsored by the European Union and activities under the framework of the Intergovernmental Panel on Climate Change (IPCC). This has lead to the completion of large ensembles of simulations of European climate change with coupled Atmosphere-ocean general circulation models (AOGCMs) and regional 
climate models (RCMs). Present day AOGCMs have typical horizontal resolutions of a few hundred $\mathrm{km}$, and can thus provide information on the broad scale patterns of change. Driven at the lateral boundaries by AOGCM fields, RCMs can be run at resolutions of a few tens of $\mathrm{km}$ and can thus regionally enhance the AOGCM information and provide fine scale climate change data [7]. This is particularly important for the European region, which is characterized by complex topography, coastlines and land-use distribution and spans a wide range of climate types, from semi-arid in the southern Mediterranean regions to cold-wet in Northern Europe.

It is beyond the purpose of this paper to assess the multitude of European climate change papers available in the literature. However, two ensembles of simulations have been recently completed which can provide the most updated information on climate change projections over Europe. The first consists of the coordinated set of AOGCM simulations for the $20^{\text {th }}$ and $21^{\text {st }}$ century recently completed in support of the IPCC Fourth Assessment Report (AR4). This ensemble of unprecedented size and quality is referred to as CMIP3 and includes simulations with over 20 models from laboratories worldwide and three GHG emission scenarios from IPCC [8]. The second ensemble was produced as part of the recently completed EU project PRUDENCE [9], in which $10 \mathrm{RCMs}$ were used to produce $21^{\text {st }}$ century climate change scenarios over the European region for two different GHG IPCC emission scenarios. Presently, the PRUDENCE experiments can be considered as the most up-to-date published RCM-based high resolution ensemble of climate change projections over the European region.

Most of our assessment is thus based on the CMIP3 and PRUDENCE ensembles of simulations. We focus on surface air temperature and precipitation, two of the most important and well studied variables of relevance for impact assessment studies, and on the seasonal to longterm temporal scales. Some information on changes in daily events and short term extremes available from previous work is also reviewed.

The paper is organized as follows. Section 2 first presents a brief overview of previous work concerning climate change projections over Europe. This is not meant to be a comprehensive review, but only to provide some basic information about the literature available on this topic. Section 3 briefly describes the CMIP3 and PRUDENCE datasets, while section 4 presents the results from our analysis. Finally, Section 5 presents our final considerations.

\section{Brief overview of available literature on European climate change projections}

As already mentioned, a multitude of papers are available in the literature on climate change projections over Europe, produced with both global and regional climate models, and it is beyond the purpose of this paper to present a full review of them. Comprehensive assessments of the literature on climate projections at the regional scale, including the European region, can be found in the regional projection chapters of the third and fourth assessment reports $[6,10]$.

Model-based assessments of European climate change scenarios have essentially employed two types of approaches. The first consists of investigating regional-scale projections by more or less large ensembles of AOGCM simulations. This has been done with successive generations of models, focusing in particular on issues of uncertainty and inter-model consistency of simulated changes $[3-6,11-15]$. The analysis of AOGCM ensembles has addressed not only mean changes but also changes in interannual variability and extremes [16-23]. As mentioned, the most advanced ensemble of AOGCM simulations that can be used for climate change assessment studies is the CMIP3 [24] and this will provide the basis for the analysis presented in this paper (see section 4 ).

AOGCM studies have provided only a broad scale view of climate change patterns over Europe due to the relatively coarse resolution of the models. Different regionalization techniques, including both dynamical (or physical model-based) and statistical downscaling approaches, have however been utilized to produce fine scale climate projections. In fact the European modeling community has been at the forefront of the development and application of regionalization techniques. In particular, variable resolution and nested RCMs have been extensively used over the European region. 
The first application of a nested RCM over Europe is that of Giorgi et al. [25], who performed sets of month-long simulations driven by present day GCM simulations. This was followed by corresponding climate change experiments, still based on ensembles of month-long simulations, by Marinucci et al. [26] and Giorgi et al. [27]. The first continuous multi-year RCM simulations over the region were carried out by Jones et al. [28] and Christensen et al. [29], while the first simulations with a variable resolution GCM were completed by Deque and Piedelievre [30].

Since then, mostly as part of a series of EU projects, a number of climate change projections over Europe or some of its sub-regions have been carried out with RCMs, either for $2 \mathrm{XCO} 2$ forcing or for transient GHG emission scenarios. These include Giorgi et al. [31], Rotach et al. [32], Jones et al. [33], Deque et al. [34], Machenauer et al. [35], Raisanen et al. [36], Raisanen and Joelsson [37], Rummukainen et al. [38], Beniston et al. [39], Christensen and Christensen [40,41], Kjellstrom [42], Semmler and Jacob [43], Sanchez et al. [44], Pal et al. [45], Schar et al. [46]; Giorgi et al. [47]; Raisanen et al. [48]; Ekstrom et al. [49], Deque et al. [50], Gao et al. [51], Diffenbaugh et al. [52].

As mentioned, the most comprehensive ensemble of RCM-based climate change simulations over Europe is that completed as part of the EU project PRUDENCE [9]. PRUDENCE has been a landmark project that allowed huge strides in our understanding of the uncertainties related to European climate change. The main results from PRUDENCE are reported in a special issue of Climatic Change appeared in May of 2007. In particular, papers that analyze different aspects of the PRUDENCE climate change scenarios include Christensen and Christensen [53], Jacob et al. [54], Deque et al. [55], Beniston et al. [56], van Ulden et al 57], Vidale et al. [58], Lenderink et al. [59], Kjellstrom et al. [60], Rockel and Woth [61], and De Castro et al. [62].

A critical aspect of climate change projections for the European region is that they have shown remarkable consistency across different generations of models and different scenarios. Therefore, although we show here only patterns based on the CMIP3 and PRUDENCE projections, these are also indicative of earlier projections. In the next section we provide a brief description of the CMIP3 and PRUDENCE datasets.

\section{Experiments and datasets}

The European region of interest in this study is shown in Figure 1, while the CMIP3 and PRUDENCE datasets are described in Table 1. Figure 1 shows the representation of the European topography and coastlines in the PRUDENCE RCMs (about $50 \mathrm{~km}$ grid spacing) and the finest $(\sim 120 \mathrm{~km})$ and coarsest $(\sim 450 \mathrm{~km})$ resolution CMIP3 AOGCMs. It is evident that while the RCMs provide a reasonably good representation of the main European features (although highly smoothed), even the highest resolution AOGCM provides an extremely crude representation of the European physiography. AOGCMs can thus be expected to only provide a broad scale information of the climate change patterns over the region.

We selected 18 models out of the full CMIP3 ensemble from a preliminary analysis of scenario availability and performance over the region. The CMIP3 dataset consists of (Table 1): 20 century climate simulations using observed GHG and aerosol forcing (referred to as $20 \mathrm{C}$ experiments), $21^{\text {st }}$ century climate simulations using GHG and aerosol forcing from the A1B, A2 and B1 emission scenarios of IPCC [8] (referred to as A1B, A2 and B1 experiments, respectively). This set of scenarios nearly covers the entire IPCC scenario range. The B1 is close to the low end of the range $\left(\mathrm{CO}_{2}\right.$ concentration of about $550 \mathrm{ppm}$ by 2100$)$, the A2 to the high end $\left(\mathrm{CO}_{2}\right.$ concentration of about $850 \mathrm{ppm}$ by 2100) and the $\mathrm{A} 1 \mathrm{~B}$ to the middle of the range $\left(\mathrm{CO}_{2}\right.$ concentration of about $700 \mathrm{ppm}$ by 2100). Some models include multiple realizations for the same case (Table 1), and for these we utilize the ensemble average of the realizations. Note that for interannual variability the ensemble average is taken after the calculations are made for individual models.

Monthly data for the CMIP3 experiments were obtained from the PCMDI web site (www.pcmdi-llnl.gov) and the reader is referred to this web site for more information about the participating models. To facilitate the CMIP3 model intercomparison, the data are interpolated onto a common 1-degree grid. A common 1-degree land mask grid is also defined, based 

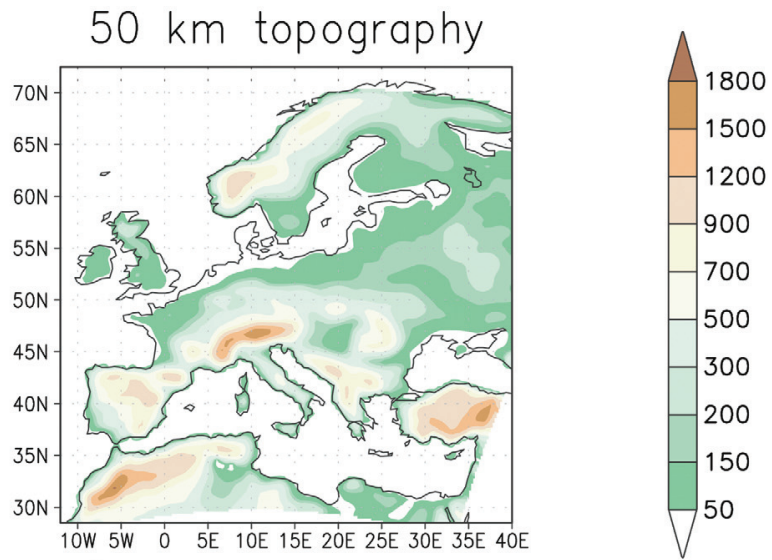

a
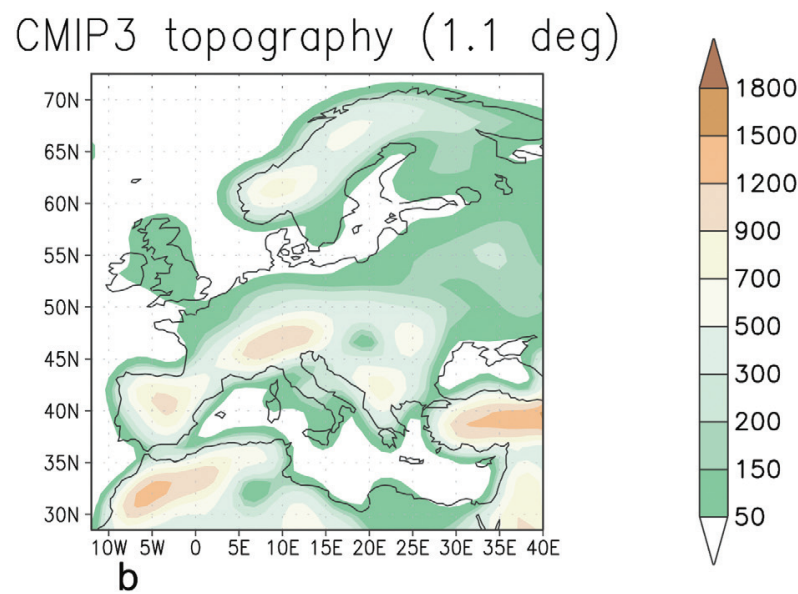

CMIP3 topography ( $4 \mathrm{deg})$
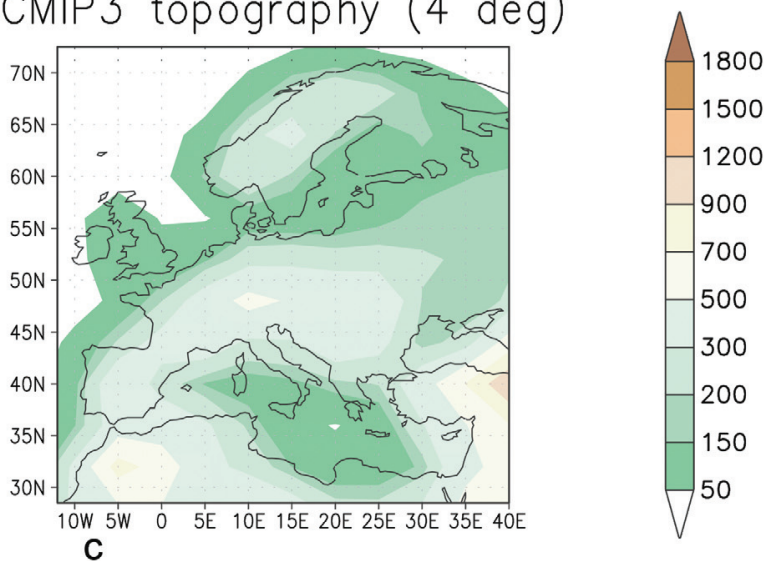

Fig. 1. Representation of the topography and coastlines of Europe at a grid spacing of (a) $50 \mathrm{~km}$ (RCM models from PRUDENCE); (b) $1.1 \mathrm{deg}$ (fine resolution AOGCM from CMIP3) (c) $4.0 \mathrm{deg}$ (coarse resolution AOGCM from CMIP3). Units are m. 
Table 1. CMIP3 and PRUDENCE models used in the analysis. For each scenario the number of available realizations is reported. In parentheses are the resolutions of the CMIP3 AOGCMs and GCMs driving the PRUDENCE RCMs.

\begin{tabular}{|c|c|c|c|c|c|c|c|c|}
\hline CMIP3 model-country-res & $20 \mathrm{C}$ & B1 & A1B & A2 & PRUDENCE model-institute & $20 \mathrm{C}$ & B2 & $\overline{A 2}$ \\
\hline BCCR-Norway $\left(1.9^{\circ}\right)$ & 1 & & & 1 & HIRHAM-DMI(HadAM3H/ECHAM4) & 8 & 2 & 7 \\
\hline CGCM-Canada $\left(2.8^{\circ}-1.9^{\circ}\right)$ & 6 & 4 & 4 & 2 & CHRM-ETH (HadAM3H) & 1 & & 1 \\
\hline CNRM-CM3-France $\left(1.9^{\circ}\right)$ & 1 & 1 & 1 & 1 & CLM-GKSS (HadAM3H) & 2 & & 2 \\
\hline CSIRO-MK-Australia $\left(1.9^{\circ}\right)$ & 2 & 1 & 1 & 1 & HadCM3-HC (HadAM3H) & 3 & 1 & 3 \\
\hline GFDL-CM2.0-USA $\left(2^{\circ} \times 2.5^{\circ}\right)$ & 3 & & 1 & 1 & RegCM-ICTP (HadAM3H) & 1 & 1 & 1 \\
\hline GFDL-CM2.1-USA $\left(2^{\circ} \times 2.5^{\circ}\right)$ & 3 & 1 & 1 & 1 & RACMO-KNMI (HadAM3H) & 1 & & 1 \\
\hline GISS-AOM-USA $\left(3^{\circ} \times 4^{\circ}\right)$ & 1 & & 2 & 1 & Arpège-CNRM(Arpege/ HadCM3H ) & 3 & 4 & 4 \\
\hline GISS-EH-USA $\left(4^{\circ} \times 5^{\circ}\right)$ & 5 & 1 & 1 & & REMO-MPI (HadAM3H) & 1 & & 1 \\
\hline INMCM-Russia $\left(4^{\circ} \times 5^{\circ}\right)$ & 1 & 1 & 1 & 1 & RCAO-SMHI(ECHAM4/ECHAM3H) & 3 & 2 & 4 \\
\hline IPSL-CM4-France $\left(2.5^{\circ} \times 3.75^{\circ}\right)$ & 1 & 1 & 1 & 1 & PROMES-UCM (HadAM3H) & 1 & 1 & 1 \\
\hline MIROCH-Japan $\left(1.1^{\circ}\right)$ & 1 & & 1 & & & & & \\
\hline MIROCM-Japan $\left(2.8^{\circ}\right)$ & 3 & 3 & 3 & 3 & & & & \\
\hline ECHO-G-Germany $/$ Korea $\left(3.9^{\circ}\right)$ & 5 & 3 & 3 & 3 & & & & \\
\hline ECHAM5/MPI-Germany $\left(1.9^{\circ}\right)$ & 3 & 3 & 2 & 3 & & & & \\
\hline MRI-CGCM-Japan $\left(2.8^{\circ}\right)$ & 5 & 5 & 5 & 5 & & & & \\
\hline NCAR-CCSM3-USA $\left(1.4^{\circ}\right)$ & 8 & 8 & 6 & 4 & & & & \\
\hline NCAR-PCM-USA $\left(2.8^{\circ}\right)$ & 4 & 2 & 3 & 4 & & & & \\
\hline UKMO-HadCM3-UK $\left(2.5^{\circ} \times 3.75^{\circ}\right)$ & 1 & 1 & 1 & 1 & & & & \\
\hline UKMO-HadGEM-UK $\left(1.3^{\circ} \times 1.9^{\circ}\right)$ & 1 & & 1 & & & & & \\
\hline
\end{tabular}

on the half-degree grid of the observed dataset from the Climatic Research Unit (CRU) of the University of East Anglia [63]. The CRU dataset is also interpolated onto the 1 degree grid and is used for model evaluation.

The PRUDENCE dataset includes an ensemble of ten RCMs [9] performing sets of simulations of 30-year length, one for the present day reference period of 1961-1990, and the others for the future period of 2071-2100 with forcing from the A2 and B2 emission scenarios [8]. The B2 scenario also lies towards the low end of the IPCC range, with a CO2 concentration of about $620 \mathrm{ppm}$ by 2100. Table 1 describes the PRUDENCE models and simulations. The PRUDENCE RCM experiments cover the European region at a grid spacing of about $50 \mathrm{~km}$ and are driven at the lateral boundaries by different global model forcing fields (Table 1), although most of them utilize forcing from the Hadley Centre atmospheric model HadAM3H with a horizontal resolution of $1.25 \times 2.75$ degrees. The reader is referred to the PRUDENCE website (http://www.dmi.dk/f+u/klima/prudence/) for more information on the PRUDENCE experiment set up.

We note that the PRUDENCE RCMs are driven by an earlier generation of GCMs compared to those used in CMIP3, so to some extent the two ensembles can be considered as mostly independent of each other.

\section{Results}

\subsection{Evaluation of model climatology}

Before assessing the climate change scenario simulations it is important to provide an evaluation of the corresponding model performance over the region. Figures 2 and 3 show the December-January-February (DJF, winter) and June-July-August (JJA, summer) temperature and precipitation biases for the CMIP3 (left columns) and PRUDENCE (right columns) model ensembles, respectively. The biases are calculated by comparison with the CRU observations for the period 1961-1990.

Focusing on temperature first, we find a somewhat different bias distribution in the two datasets. The PRUDENCE models show an overall warm bias over most of Europe in both seasons. Exceptions are the Mediterranean region in DJF and southern Scandinavia in JJA. 

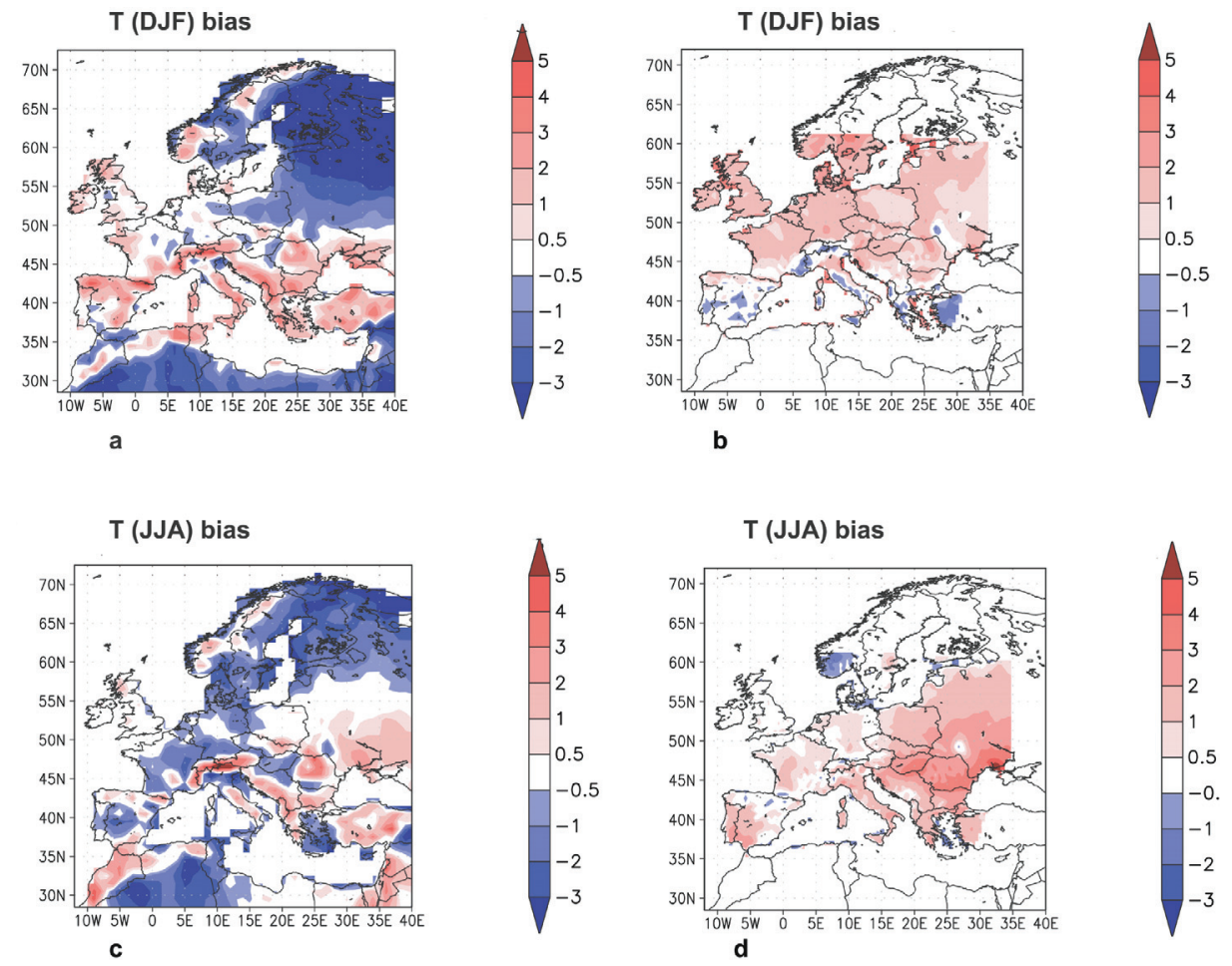

Fig. 2. Ensemble average surface air temperature bias for the CMIP3 AOGCMs (panels a, c) and the PRUDENCE RCMs (panels b, d) and for winter (DJF, top panels) and summer (JJA, bottom panels). Units are ${ }^{\circ} \mathrm{C}$ and the bias is calculated with respect to the CRU data for the period 1961-1990. Here as well as in the next figures PRUDENCE data are shown only for the domain common to all PRUDENCE RCMs.

Overall this mean PRUDENCE warm bias is not pronounced, mostly less than 2 degrees except over southeastern Europe in JJA. This last feature has been found also in previous generations of RCM simulations e.g. by Machenauer et al. [35] and thus seems to be a systematic model problem for this area.

The CMIP3 models show a quite different bias distribution, with a cold bias over Northeastern Europe in both seasons and a warm bias over the Mediterranean in DJF. We also find a general warm bias over the peaks of the main mountain chains (e.g. the Alps, Pyrenees, Balkans and Carpathians) and a corresponding cold bias in the surrounding flat regions. This is evidently due to the coarse resolution of the AOGCM model topographies (see Figure 1), which underestimate the height of the mountain peaks and overestimate the height of surrounding flat areas. Overall, also the temperature biases in the CMIP3 models are mostly less than 2 degrees.

Moving to precipitation, we find more similarities between the bias distributions in the two ensembles. In DJF, precipitation is overestimated by up to 30-40\% over most of central and northern Europe, while it is somewhat underestimated over the Mediterranean. This may be an indication of an excessively northward displacement of the Atlantic winter storm track, and appears to be a systematic feature. In JJA, both ensembles underestimate precipitation over Eastern and southeastern Europe, a feature also noted in previous generation models [35], and they slightly overestimate it over Western Europe. The magnitude of the summer bias is however smaller than in winter.

In summary, the CMIP3 and PRUDENCE ensembles provide a reasonably good simulation of the precipitation and temperature climatology over Europe. Some systematic biases do persist in this generation models compared to previous ones, such as an overestimate of temperature and underestimate of precipitation in summer over southeastern Europe and a general overestimate of winter precipitation over most of the Central European areas. 


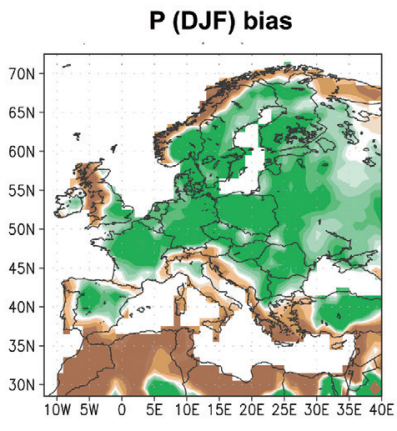

a

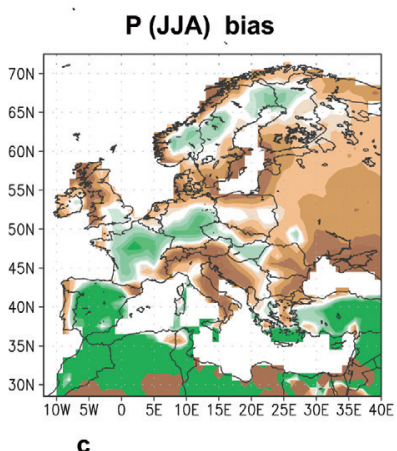

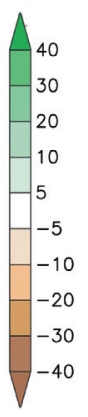
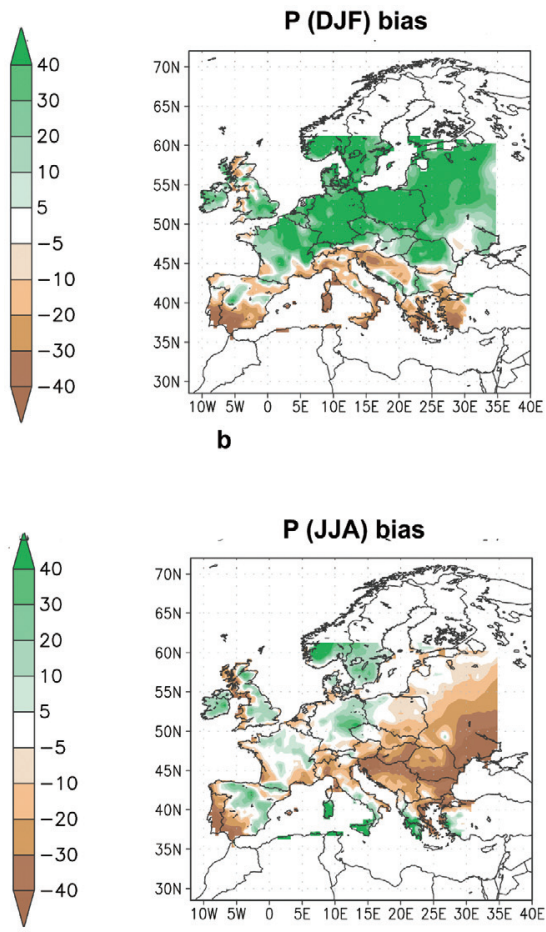

b
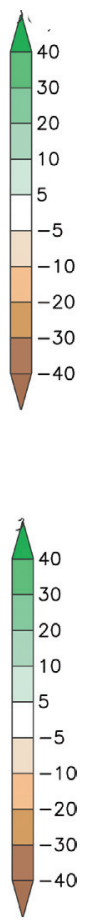

d

Fig. 3. Ensemble average precipitation bias for the CMIP3 AOGCMs (panels a, c) and the PRUDENCE RCMs (panels b,d) and for winter (DJF, top panels) and summer (JJA, bottom panels). Units are \% of observations and the bias is calculated with respect to the CRU data for the period 1961-1990.

\subsection{Mean changes}

Figures 4 and 5 show the DJF and JJA ensemble average temperature and precipitation change projections by the CMIP3 and PRUDENCE ensembles for the period 2071-2100 with respect to 1961-1990 and the A2 emission scenario, i.e. the scenario common to both ensembles. In general, very consistent patterns of change across the two ensembles can be observed. For example, maximum warming (up to 5 degrees for this high GHG concentration scenario) is found over northeastern Europe in DJF and over the Mediterranean in JJA.

The precipitation change signal shows a well defined dipolar pattern, with an increase over northern Europe and a decrease over the Mediterranean. This pattern exhibits a north-south migration, with the area of reduced precipitation moving northward from the southern Mediterranean in DJF to encompassing most of Western Europe and areas of central Europe in JJA. The precipitation changes, both positive and negative, are quite substantial, reaching values in excess of $30 \%$. This dipolar pattern of precipitation change is consistent with a northward shift of the mid-latitude storm track commonly seen in most climate change simulations [6]. It is associated with an increasing anti-cyclonic circulation over the northeastern Atlantic in summer and Central-southern Europe in winter as depicted in Figure 6. These areas of anticyclonic circulation deflect northward the path of Atlantic storms.

The consistency of the geographical and seasonal distribution of the temperature and precipitation change across the two ensembles is remarkable (Figures 4-5). As mentioned above, similar patterns were observed in previous generation global model simulations for different GHG emission scenarios [3-5]. Therefore the patterns shown in Figures $4-5$ appear to be quite robust. It is also worth noting how the PRUDENCE change signals clearly show the effects of topographical and coastline features not captured by the CMIP3 global models, for example associated with the presence of the Italian Peninsula, which calls for the use of high resolution modeling to produce spatially detailed climate change scenarios over the region. Finally we 

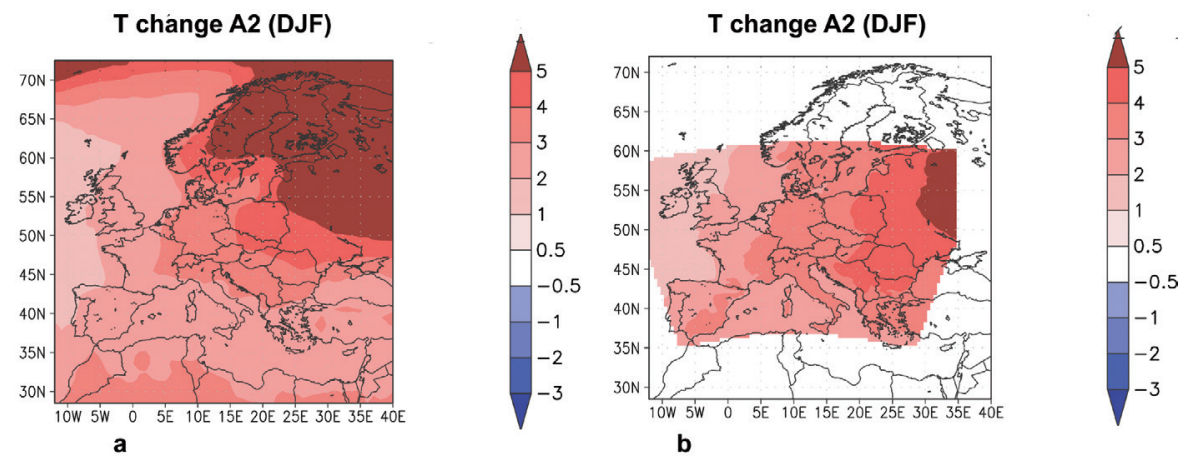

T change A2 (JJA)
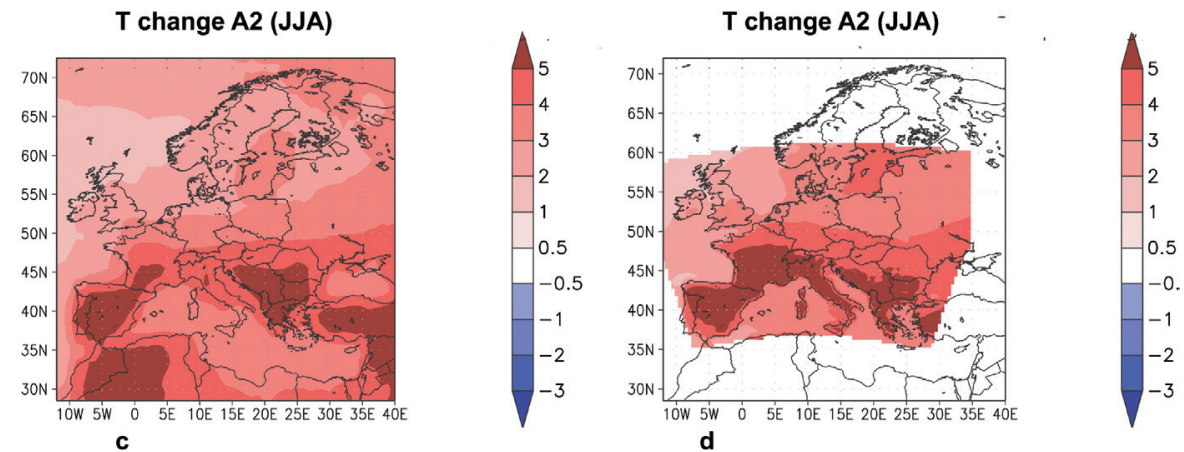

Fig. 4. Ensemble average surface air temperature change (A2 scenario, 2071-2100 minus 1961-1990) for the CMIP3 AOGCMs (panels a, c) and the PRUDENCE RCMs (panels b, d) for winter (DJF, top panels) and summer (JJA, bottom panels). Units are ${ }^{\circ} \mathrm{C}$.

observe that, also for the cases in which the biases in the CMIP3 and PRUDENCE ensembles are different (Figures 2 and 3), the change patterns remain similar (Figure 4 and 5), which is suggestive of a weak dependence of the climate change signal on the underlying model bias.

The dipolar nature of the change signals in Figures 4 and 5 suggests that two regions can be broadly identified as exhibiting internally coherent signals, Northern-central Europe and Southern Europe. These two regions are roughly divided by the latitude line of $45 \mathrm{~N}$. Having divided Europe in these two regions, Figures 7 and 8 show for temperature and precipitation the region-average changes as a function of season, emission scenario and future time period within the $21^{\text {st }}$ century. The figures are based on the CMIP3 ensemble and show not only the ensemble averaged changes but also the standard deviation of the changes across models. Cases for which this standard deviation is smaller (greater) than the mean change are indicative of a strong (weak) agreement across models.

The first feature to highlight is that, both for temperature and precipitation, the ensemble average changes consistently have the same sign across scenarios and time slices and their magnitude increases from the low GHG scenario B1 to the high GHG ones (A1B and A2) (Figure 7) and increases as we move into the later decades of the $21^{\text {st }}$ century (Figure 8). In other words, the sign of the change for these broad regions does not depend on the GHG forcing while its magnitude increases with the GHG forcing. These results are suggestive of the possibility to scale the broad regional scale signal by the global scale forcing and in turn by the global temperature change resulting from this global forcing $[64,65]$.

The seasonality of the warming signal is strong over Southern Europe, with a pronounced summer maximum and winter minimum. Conversely, over Northern-central Europe the warming is somewhat larger in winter than spring/summer. The inter-model standard deviation of the 


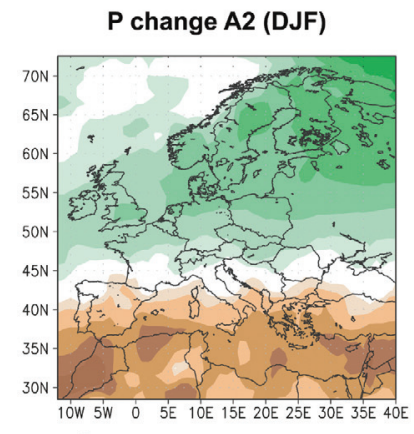

a

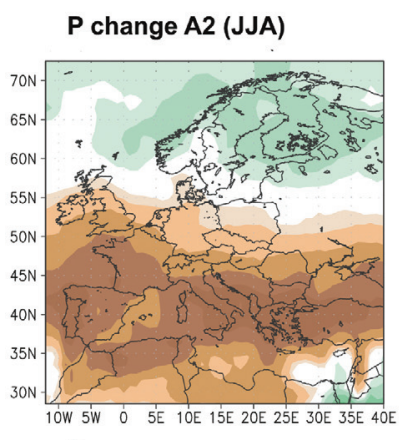

c
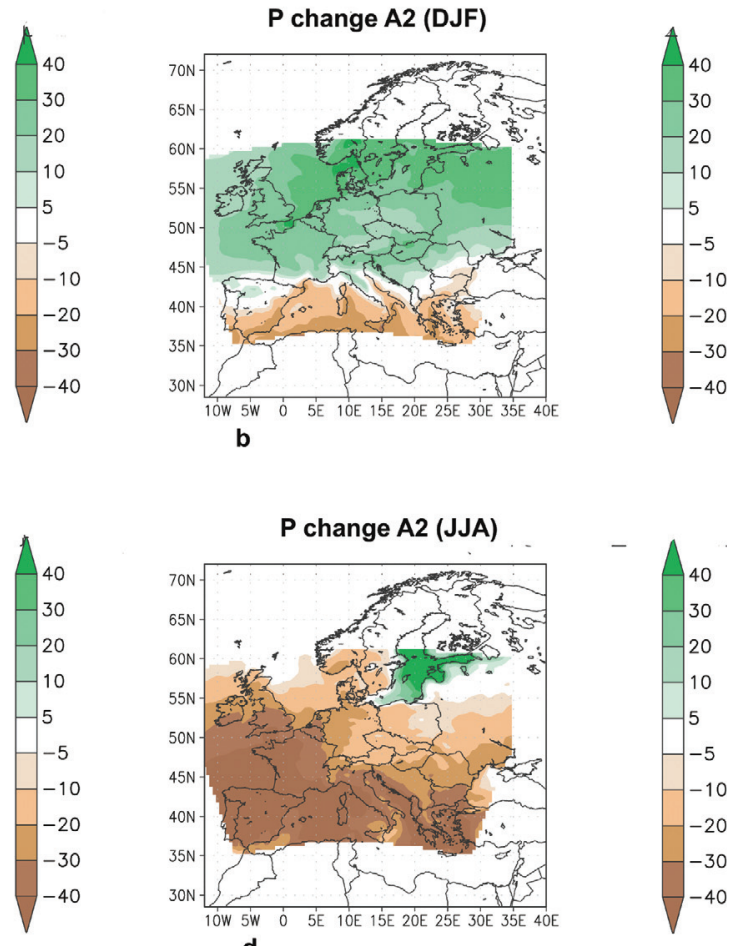

Fig. 5. Ensemble average precipitation change (A2 scenario, 2071-2100 minus 1961-1990) for the CMIP3 AOGCMs (panels a, c) and the PRUDENCE RCMs (panels b, d) for winter (DJF, top panels) and summer (JJA, bottom panels). Units are \% of 1961-1990 values.
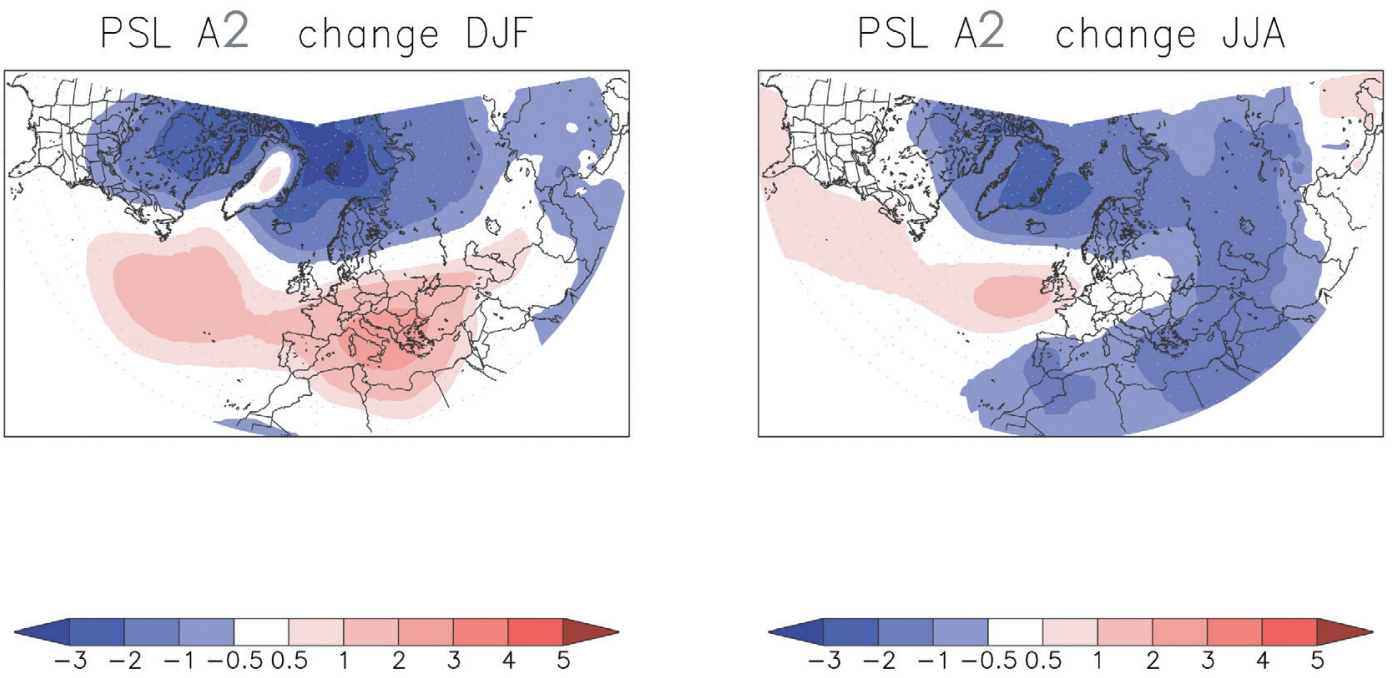

Fig. 6. Ensemble average change of sea level pressure for DJF (panel a) and JJA (panel b) in the CMIP3 ensemble, A2 scenario, 2071-2100 minus 1961-1990. Units are hPa.

warming is always lower than the ensemble mean change, indicating a high signal-to-noise ratio and therefore a robust signal. A strong seasonality is also evident in the precipitation change signal. Over Southern Europe the precipitation change is always negative, it is maximum in 


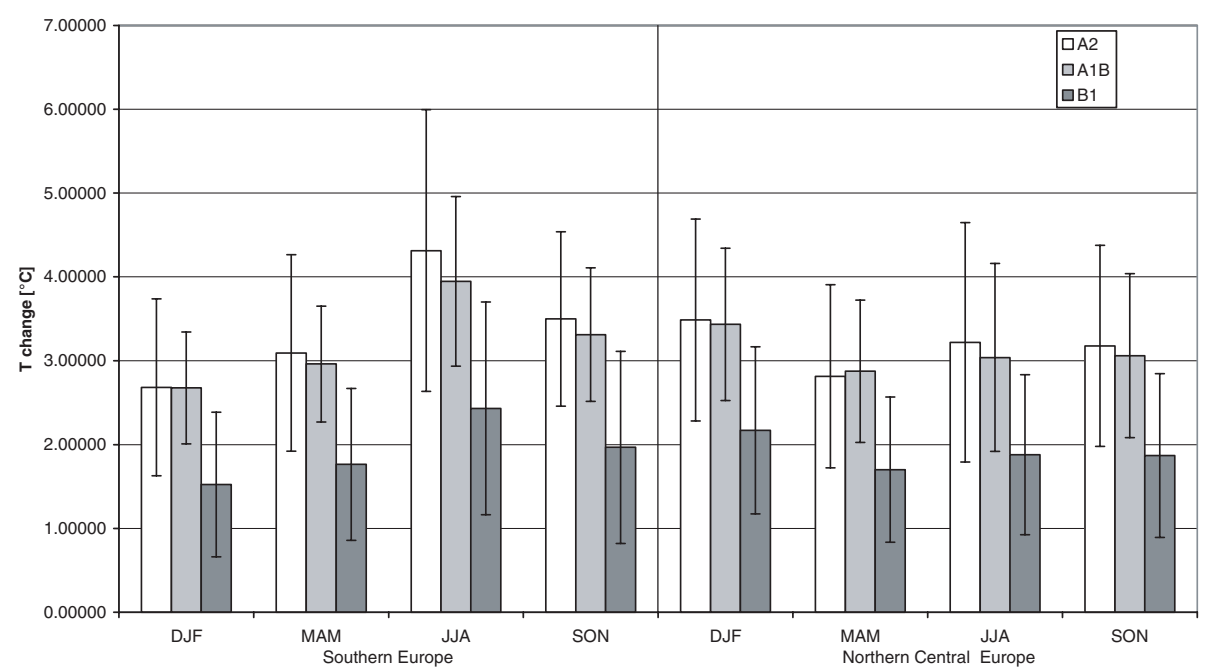

$\mathbf{a}$

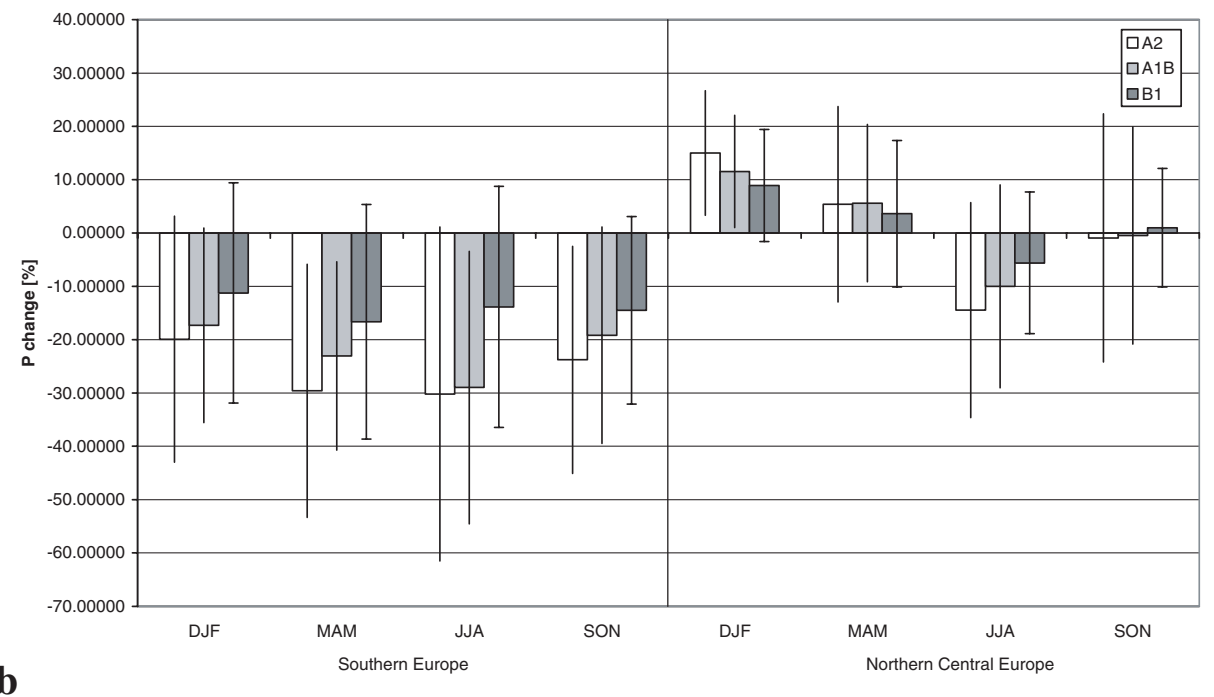

Fig. 7. Ensemble average temperature $\left({ }^{\circ} \mathrm{C}\right.$, panel $\left.a\right)$ and precipitation $(\%$, panel $b)$ changes over the Northern Central Europe (left) and Southern Europe (right) regions for the A2, A1B and B1 scenarios. For each mean change value the corresponding inter-model standard deviation of the changes is reported.

summer and minimum in winter and in the range of $-10 \%$ to $-40 \%$. Over Northern-central Europe, the precipitation change has a maximum positive value in winter, it decreases in spring, becomes negative in summer and close to 0 in the fall. The inter-model standard deviation of the precipitation changes is generally high, indicating a relatively large model scatter. It is smaller than the mean change over Southern Europe in spring and summer and over Northern Europe in winter only for the higher GHG emission scenarios and time slices. These are thus the cases in which the signal is most robust. In the intermediate seasons the inter-model standard deviation of the precipitation change is generally greater than the ensemble average signal, indicating a relatively pronounced disagreement across models not only for the magnitude but also for the sign of the change. 


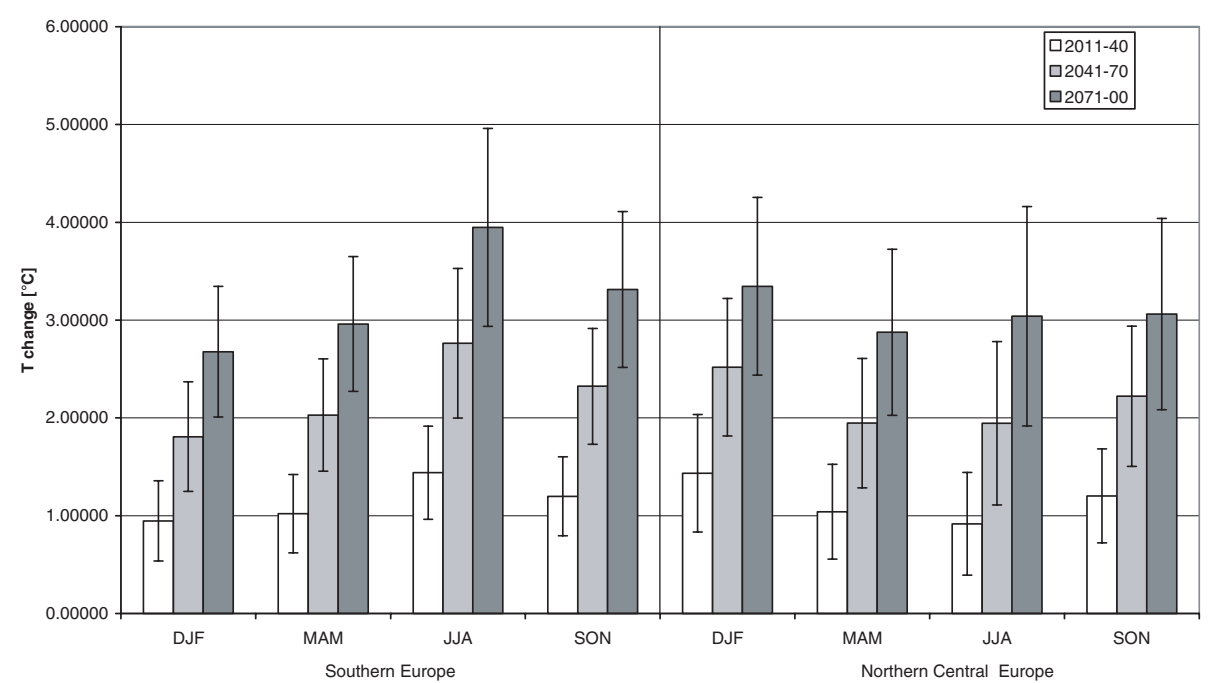

$\mathbf{a}$

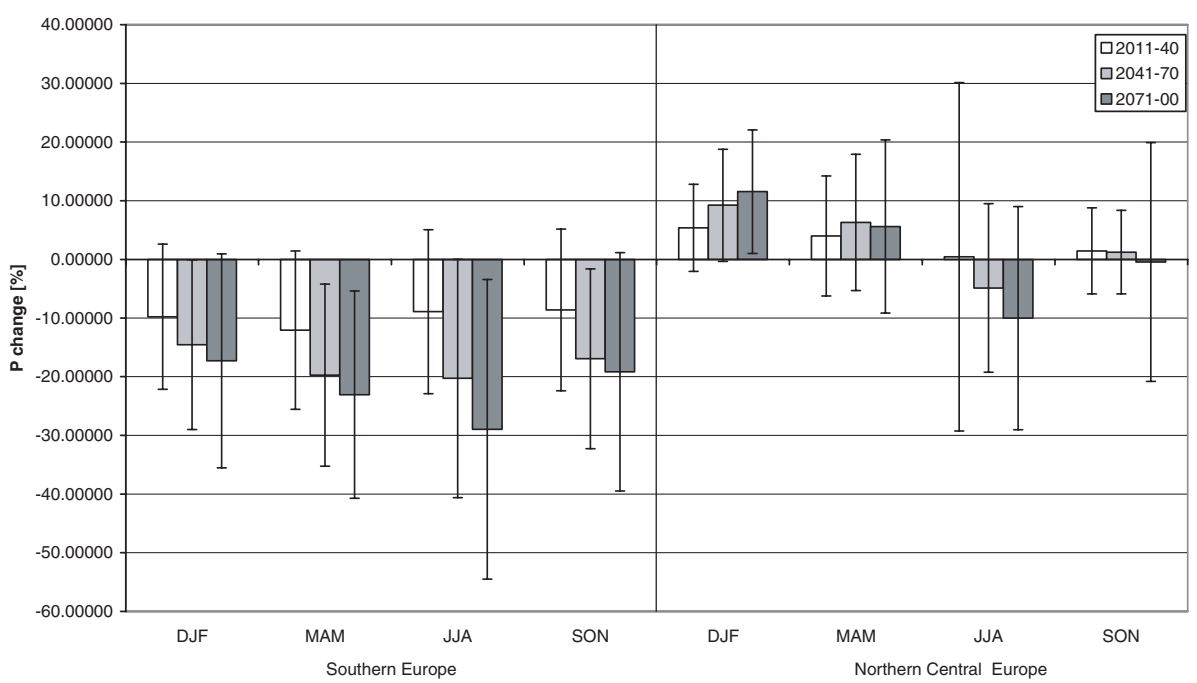

b

Fig. 8. CMIP3 ensemble average temperature $\left({ }^{\circ} \mathrm{C}\right)$ (panel a) and precipitation (\%) (panel b) change (with respect to 1961-1990) for the A1B scenario when different future time periods are considered (2011-2040, 2041-2070, 2071-2100). For each mean change value the corresponding inter-model standard deviation of the changes is reported.

\subsection{Changes in interannual variability}

Ensemble average changes in temperature and precipitation interannual variability are shown in Figures 9 and 10, respectively. Temperature variability is measured by the interannual standard deviation, while precipitation variability is measured by the coefficient of variation, i.e. the standard deviation divided by the mean [17]. The changes are calculated for the period 20712100 with respect to $1961-1990$ and for the A2 scenario.

We find again a substantial consistency across the two ensembles. A decrease in temperature variability is projected to occur throughout most of Europe in the winter. This decrease in cold season temperature variability is consistent with previous analyses of climate change simulations 


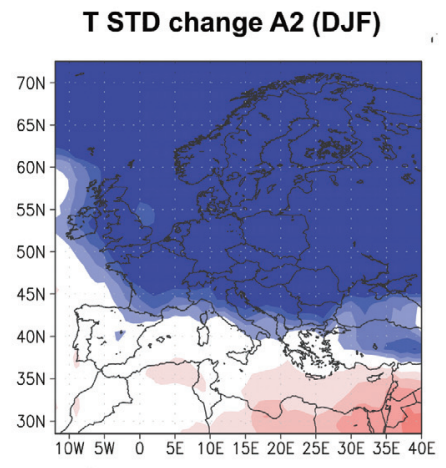

a

T STD change A2 (JJA)

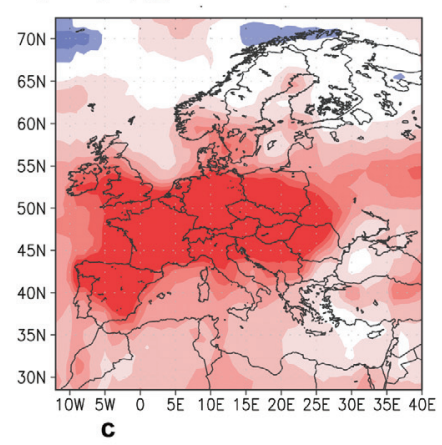

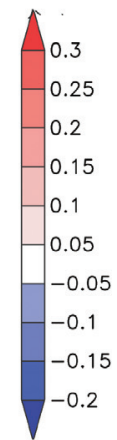

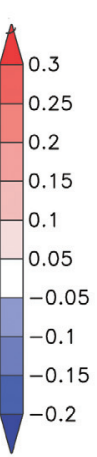

T STD change A2 (DJF)

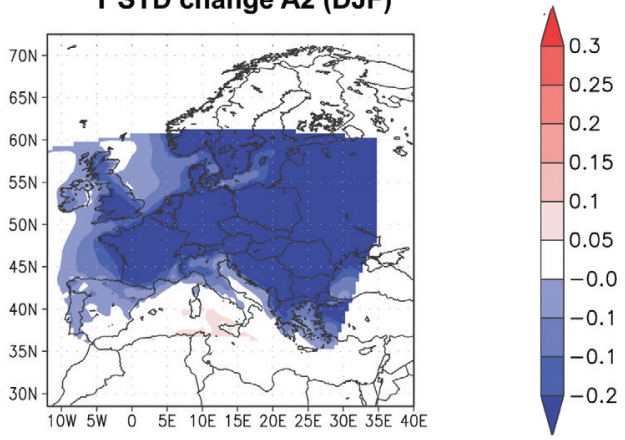

b

T STD change A2 (JJA)

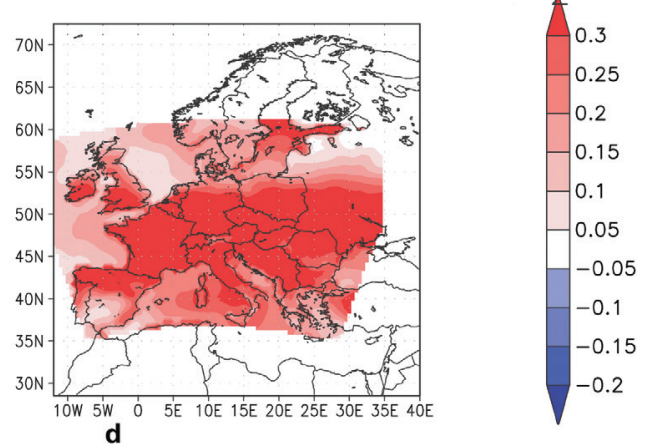

Fig. 9. Ensemble average change in surface air temperature interannual variability (A2 scenario, 20712100 minus 1961-1990) for the CMIP3 AOGCMs (panels a, c) and the PRUDENCE RCMs (panels b, d) for winter (DJF, top panels) and summer (JJA, bottom panels). Units are \% of 1961-1990 values. The interannual variability is measured by the interannual standard deviation.

by Raisanen [17] and Giorgi and $\mathrm{Bi}$ [19]. It has been attributed primarily to a reduction of snow cover in warmer conditions and an associated weakening of the snow albedo feedback mechanism, which tends to increase variability. Conversely, summer temperature variability increases over most of Europe, a result also consistent with previous findings $[17,19,46,47]$. It has been attributed, at least partially, to an enhanced efficiency of soil moisture-temperature feedbacks in the drier soil conditions found in future warmer climates.

Winter precipitation variability shows an increase over the Southern Mediterranean regions and only small changes in Northern-Central Europe. This area of increased variability migrates to the north during the summer to eventually cover most of continental Europe. Also this predominant increase in precipitation variability, particularly in warm climates, is in line with previous findings $[17,19]$ and has been mostly attributed to a more intense hydrologic cycle and stronger soil moisture-precipitation feedbacks in warmer conditions. It is likely that in the summer the increases in temperature and precipitation variability are coupled to each other.

\subsection{Changes in the distribution of seasonal climate anomalies}

Changes in mean and interannual variability imply shifts as well as changes of shape in the distribution of seasonal anomalies. These in turn are important because they imply changes in the occurrence of extreme seasons, which are particularly important in determining the impacts of climate change. In this section we therefore analyze the distribution of seasonal 

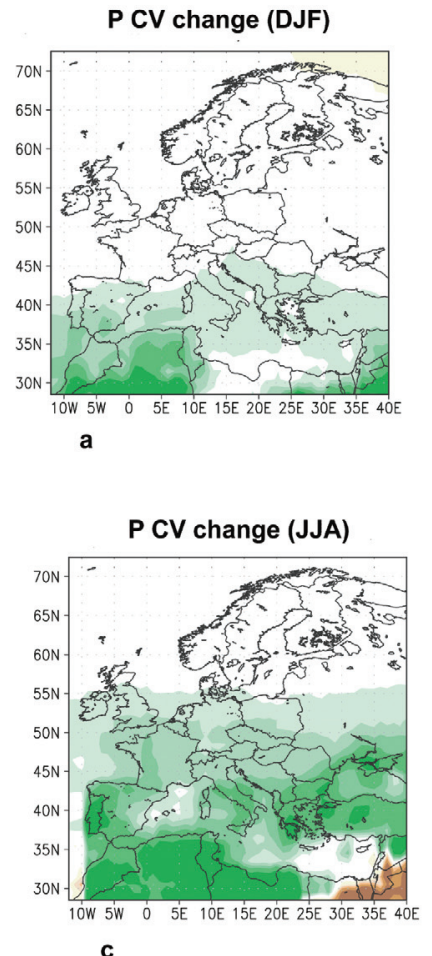
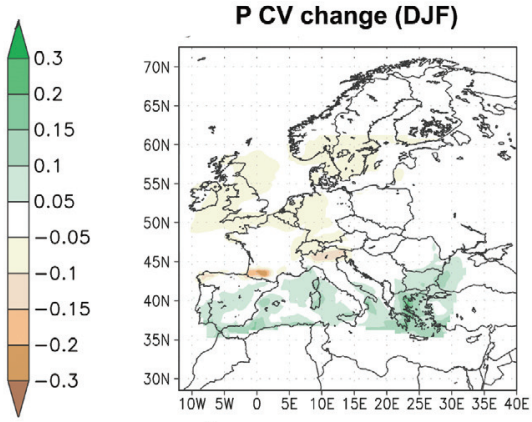

b

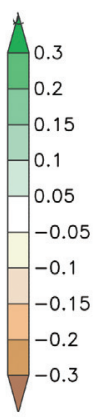

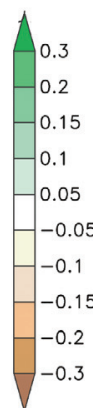

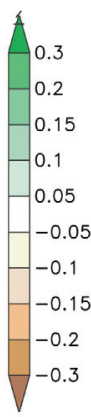

Fig. 10. Ensemble average change in precipitation interannual variability (A2 scenario, 2071-2100 minus 1961-1990) for the CMIP3 AOGCMs (panels a, c) and the PRUDENCE RCMs (panels b, d) for winter (DJF, top panels) and summer (JJA, bottom panels). Units are \% of 1961-1990 values. The interannual variability is measured buy the interannual coefficient of variation.

temperature and precipitation anomalies in present day and future climate conditions. We limit our analysis to the CMIP3 data, noting that similar conclusions are obtained with the PRUDENCE simulations.

Figures 11 and 12 show histograms of individual seasonal anomalies for DJF and JJA with respect to the ensemble average mean for the 1961-1990 reference period. The anomalies are calculated and intercompared for the 1961-1990 (black continuous histograms) and 2071-2100 (red dashed histograms) periods and for all available CMIP3 simulations. Each histogram is normalized by the total number of available simulated seasons, which is different for the reference and A2 periods (see Table 1). As a result, the histograms can be considered as discrete probability density functions (PDFs) of seasonal anomalies. Results are reported for temperature and precipitation averaged over the Northern-Central and Southern Europe regions.

For temperature (Figure 11), we find that the PDFs for the reference period are generally symmetric and relatively narrow in both regions (within $+/-2 \mathrm{C}$ ), except DJF over Northern-Central Europe, where the PDF is relatively broad (within $+/-4 \mathrm{C}$ ). For this last case, in the future projection we find that the PDF shifts towards warmer values but also becomes narrower as a result of the previously noted decrease in cold season temperature variability. The opposite is found in the other three cases, especially in summer over southern Europe, when the PDF not only shows a considerable shift but also a substantial widening and flattening. This is consistent with the increase in warm season temperature interannual variability discussed above. An important consequence of this result is that the temperature of extreme warm seasons increases relatively more than the mean temperature, i.e. that more extreme warm summers are projected to occur. Also note that the Northern-Central Europe 


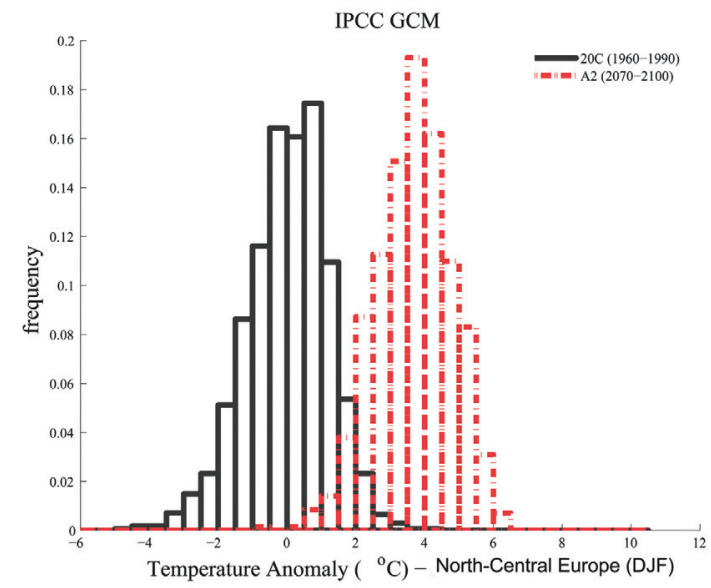

$\mathbf{a}$

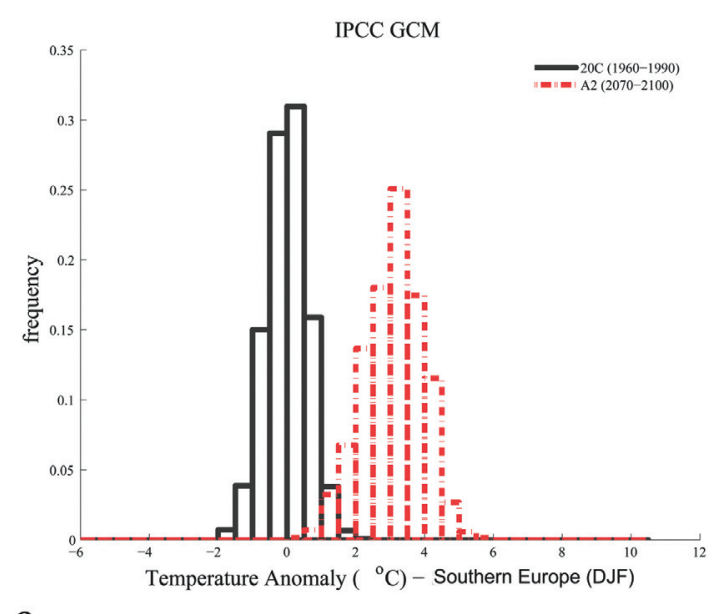

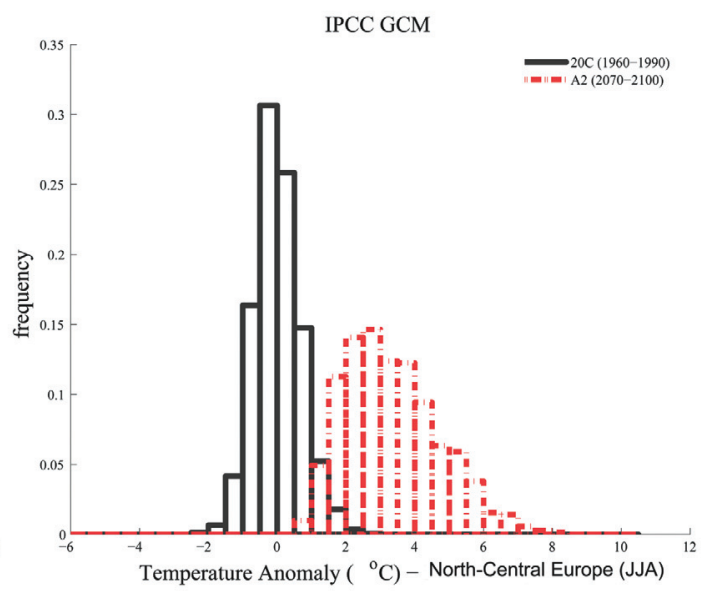

b

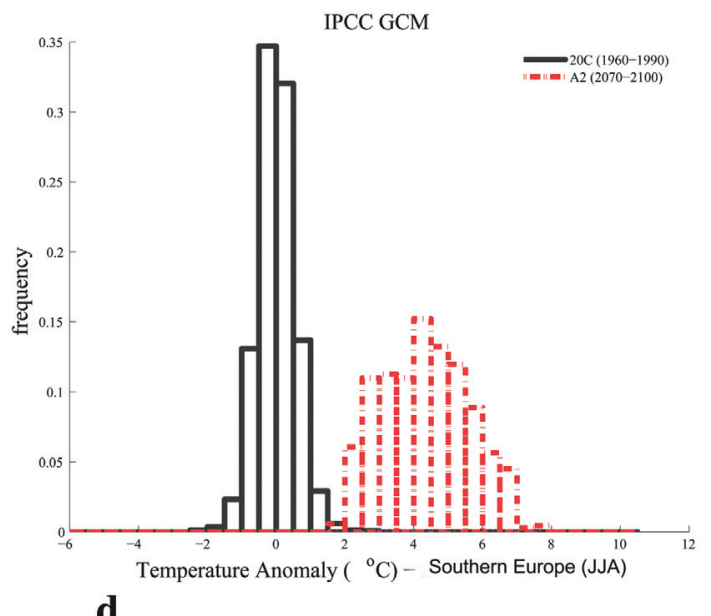

d

Fig. 11. Normalized distribution of seasonal temperature anomalies in the CMIP3 AOGCMs for 19611990 (black line) and 2071-2100 (A2 scenario) scenario period (red line) over Northern Central Europe for DJF (panel a), JJA (panel b) and over Southern Europe for DJF (panel c), JJA (panel d). The anomaly values are reported ${ }^{\circ} \mathrm{C}$ on the $\mathrm{x}$ axis; the $\mathrm{y}$ axis reports the normalized frequency of occurrence. The anomalies are calculated with respect to the 1961-1990 mean.

summer temperature PDF becomes asymmetric in the future projection, with a longer warm tail, which is also an indication of a relatively greater increase of extreme warm seasons.

The seasonal precipitation anomaly PDFs offer various considerations (Figure 12). Over Northern-Central Europe precipitation is abundant in both summer and winter, and therefore the seasonal anomaly PDFs are relatively narrow and nearly symmetric. The anomalies are generally within $+/-50 \%$ of the long term mean. For both seasons, consistently with the increase in variability noted above, the PDFs become broader and flatter, with an increase of positive anomalies in DJF and an increase of negative anomalies in JJA. Over the Mediterranean we find generally broader precipitation distributions in the reference period, especially in JJA, which is the dry season over the region. In both seasons the precipitation PDFs show a broadening and flattening, with a pronounced increase in negative anomaly events. This is particularly noticeable in summer where the PDF becomes substantially asymmetric and a sizeable fraction of events with anomalies greater than $-50 \%$ occur. Figures 11 and 12 are thus indicative of a marked increase in the occurrence of extreme hot and dry summers over the broad Mediterranean region identified here. 

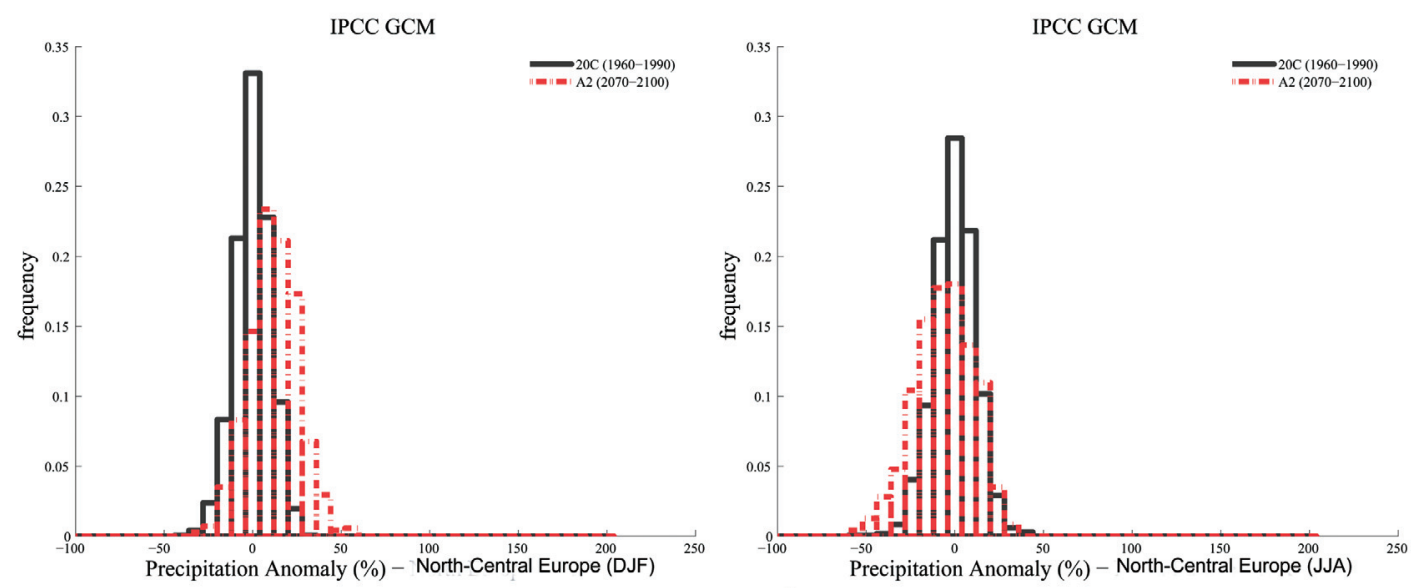

$\mathbf{a}$

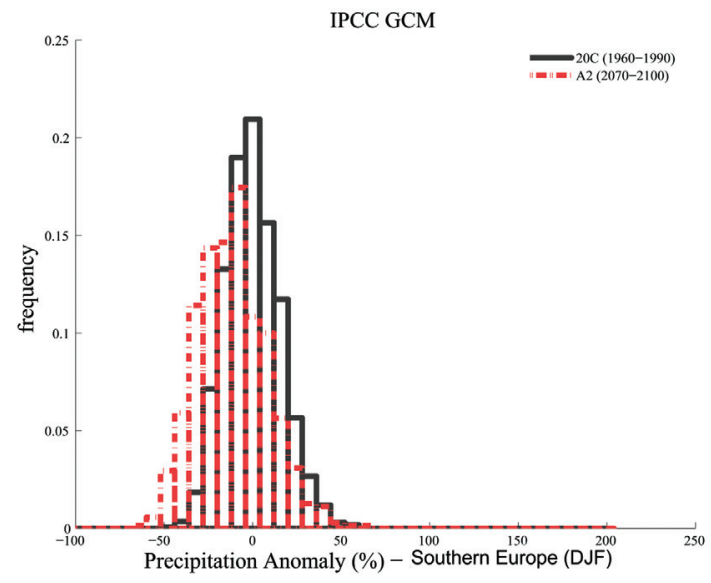

b

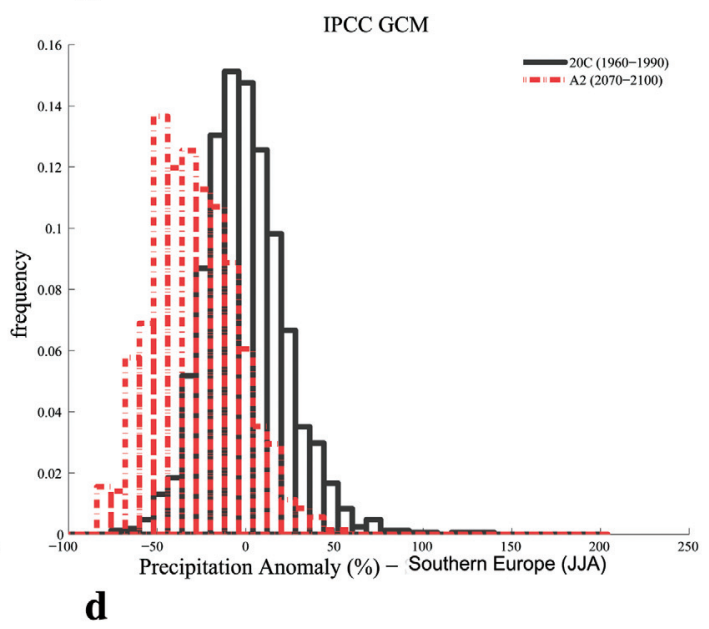

Fig. 12. Normalized distribution of seasonal precipitation anomalies in the CMIP3 AOGCMs for 19611990 (black line) and 2071-2100 (A2 scenario) scenario period (red line) over Northern Central Europe for DJF (panel a), JJA (panel b) and over Southern Europe for DJF (panel c), JJA (panel d). On the $\mathrm{x}$ axis the precipitation anomaly is reported in percent.; the $\mathrm{y}$ axis reports the normalized frequency of occurrence. The anomalies are calculated with respect to the 1961-1990 mean.

\section{Summary and conclusions}

Our main conclusions based on the analysis of climate change scenarios over the European region from the recently completed ensembles of global (CMIP3) and regional (PRUDENCE) climate change simulations for different IPCC emission scenarios can be summarized as follows:

1. There is a general consistency between the projections obtained with the CMIP3 and PRUDENCE ensembles, even though they were completed with different modeling systems and showed different systematic biases over the region.

2. We find a seasonally and latitudinally varying mean change signal. $21^{\text {st }}$ century warming of up to several degrees occurs in all seasons, and it is maximum in summer over the Mediterranean region and in winter over North-central Europe. The precipitation change signal shows a north-south dipolar pattern, with increased precipitation over northern Europe and decreased precipitation over southern Europe and the Mediterranean. This dipolar patterns is characterized by a seasonal northward migration from the winter to the summer season. It 
is consistent with an increasingly positive phase of the North Atlantic Oscillation, a feature also found by Terray et al. [66] and Coppola et al. [67].

3. Interannual variability generally increases for precipitation in all seasons and for temperature in summer, especially over the Mediterranean. It decreases for winter temperature throughout most of Europe while it shows small changes in the intermediate seasons (not shown).

4. The seasonal temperature anomaly PDFs show a shift as well as a broadening and flattening in future climate conditions in summer over both Northern-central and Southern Europe. This implies larger increases for extreme hot seasons than mean summer temperatures. In winter over Northern-Central Europe the temperature anomaly PDF becomes narrower as a result of decreased variability. The precipitation seasonal anomaly PDFs are greatly affected in summer, especially over Southern Europe, with a strong increase of events with small or negligible precipitation. These results are indicative of an increase in very dry and hot (drought prone) summer seasons throughout Europe.

5. At the broad scale, the sign of the change is little dependent on the GHG forcing, while its magnitude increases with the forcing. The magnitudes of change are thus greater for the $\mathrm{A} 2$ and A1b than the B1 and B2 scenarios and increase for the later decades of the $21^{\text {st }}$ century.

Concerning changes in daily event statistics, we can refer to previous work. For example, Giorgi et al. [47] analyzed changes in daily precipitation statistics over different European regions and found that the precipitation decrease in spring, summer and fall over the Mediterranean was mostly attributable to a decrease in the frequency of events rather than the intensity. This implies longer and warmer drought periods over the region, as also found by Pal et al. [45] and Gao et al. [59]. The increase of winter precipitation over central and northern Europe was attributed to an increase of both frequency and intensity of events.

Beniston et al. [56] analyzed different types of extremes in the PRUDENCE simulations. Their conclusions can be summarized as follows: i) Increase in frequency, intensity and duration of heat waves across Europe, with the intensity of warm extremes increasing more than the mean; ii) Increase of heavy winter precipitation over northern Europe and heavy summer precipitation over northeastern Europe, decrease of heavy precipitation and longer droughts over Southern Europe; iii) Increase of extreme wind speeds between $45 \mathrm{~N}$ and $55 \mathrm{~N}$; more intense storms and storm surges over the North Sea coasts. This last result was confirmed by Rockel and Woth [61]. Kjellstrom et al. [60] analyzed daily maximum and minimum temperature extremes under warmer scenario conditions and found increases of both extremes greater than the increase in mean temperature.

As already mentioned, the main climate change signals simulated over Europe have been extremely consistent for various generations of model projections and for different scenarios [3-5]. In addition, for the larger changes (e.g. all temperature changes, the summer drying over southern Europe and the increased winter precipitation over Northern Europe) the inter-model spread is lower than the signal itself. All this adds robustness to the reliability of the signals, a robustness that is further increased by the consistency found between some of these signals and observed trends in the late 21 th century [45]. We however stress that the signal obtained from ensembles of models filters out multidecadal variability, which in reality is important at the regional scale. Therefore, an actual climate change scenario should include not only the mean change signal but also a measure of the multidecadal variability [68].

Finally, a prominent aspect of the climate change signal over Europe as obtained from $21^{\text {st }}$ century ensemble simulations is its latitudinal and seasonal dependence. Both the mean and interannual variability changes of temperature and precipitation show a north-south structure which migrates throughout the year in an internally consistent way. Giorgi and Coppola [1] suggest that this feature, which they call the European Climate change Oscillation, or ECO, might be an intrinsic feature of the European climate change signal which can be used for detection/attribution studies and for prediction purposes. In general, the changes in temperature and precipitation over Europe are pronounced, which makes this region potentially vulnerable to GHG-induced global warming. 
We acknowledge the modeling groups, the Program for Climate Model Diagnosis and Intercomparison (PCMDI) and the WCRP's Working Group on Coupled Modelling (WGCM) for their roles in making available the WCRP CMIP3 multi-model dataset. Support of this dataset is provided by the Office of Science, U.S. Department of Energy. We also acknowledge the modeling groups participating in the PRUDENCE project for making available their data.

\section{References}

1. F. Giorgi, E. Coppola, Geophys. Res. Lett. 34, L21703 (2007)

2. F. Giorgi, Geophys. Res. Lett. 33, L08707 (2006)

3. T.G.F. Kittel, F. Giorgi, G.A. Meehl, Clim. Dyn. 14, 1 (1998)

4. F. Giorgi, et al., Geophys. Res. Lett. 28, 3317 (2001)

5. F. Giorgi, X. Bi, Geophys. Res. Lett. 32, L21715 (2005)

6. J.H. Christensen, et al., in Climate Change 200\%. The Physical Science Basis, edited by S. Solomon et al. (Cambridge University Press, Cambridge, UK, 2007), p. 847

7. F. Giorgi, J. Phys. IV (France) 139, 101 (2006)

8. Intergovernmental Panel on Climate Change (IPCC), Special Report on Emission Scenarios, edited by N. Nakicenovic et al. (Cambridge University Press, New York, 2000), p. 599

9. J.H. Christensen, T.R. Carter, M. Rummukainen, G. Amanatidis, Clim. Change 81, 1 (2007)

10. F. Giorgi, et al., Climate Change 2001: The Scientific Basis, edited by J.T. Houghton et al. (Cambridge University Press, Cambridge, UK, 2001), p. 583

11. E. Barrow, M. Hulme, M. Semenov, Clim. Res. 7, 195 (1996)

12. M. Hulme, O. Brown, Clim. Res. 10, 1 (1998)

13. F. Giorgi, R. Francisco, Geophys. Res. Lett. 27, 1295 (2000)

14. M. Hulme, J. Crossley, D. Lister, K.R. Briffa, P.D. Jones, in Interim Annual Report (CRU, Norwick, UK, 2000)

15. J. Raisanen, J. Clim. 14, 2088 (2001)

16. J. Raisanen, T.N. Palmer, J. Clim. 14, 3212 (2001)

17. J. Raisanen, J. Clim. 15, 2395 (2002)

18. J. Raisanen, Clim. Dyn. 24, 309 (2005)

19. F. Giorgi, X. Bi, Geophys. Res. Lett. 32, L13701 (2005)

20. G.A. Meehl, C. Tebaldi, Science 305, 994 (2004)

21. D.P. Rowell, Clim. Dyn. 25, 837 (2005)

22. R. Clark, S. Brown, J. Murphy, J. Clim. 19, 4418 (2006)

23. K. Ruosteenoja, H. Tuomenvirta, K. Jylha, Clim. Change (2007)

24. G.A. Meehl, et al., Bull. Amer. Meteorol. Soc. 88, 1383 (2007)

25. F. Giorgi, M.R. Marinucci, G. Visconti, J. Geophys. Res. 95, 18413 (1990)

26. M.R. Marinucci, F. Giorgi, J. Geophys. Res. 97, 9989 (1992)

27. F. Giorgi, M.R. Marinucci, G. Visconti, J. Geophys. Res. 97, 10011 (1992)

28. R.G. Jones, J.M. Murphy, M. Noguer, Quarterly J. Royal Meteorol. Soc. 121, 1413 (1995)

29. J.H. Christensen, O.B. Christensen, B. Machenhauer, in Third International Conference on Modeling of Global Climate Change and Variability, Hamburg, Germany, 1995

30. M. Deque, J.P. Piedelievre, Clim. Dyn. 11, 321 (1995)

31. F. Giorgi, J.W. Hurrell, M.R. Marinucci, M. Beniston, J. Clim. 10, 288 (1997)

32. M.W. Rotach, et al., Theor. Appl. Clim. 57, 209 (1997)

33. R.G. Jones, J.M. Murphy, M. Noguer, A.B. Keen, Quarterly J. Roy. Meteorol. Soc. 123, 265 (1997)

34. M. Deque, P. Marquet, R.G. Jones, Clim. Dyn. 14, 173 (2004)

35. B. Machenhauer, et al., Validation and analysis of regional present-day climate and climate change simulations over Europe, MPI, Hamburg, Germany, 1998

36. J. Raisanen, et al., SHMI Reports Meteorology and Climatology, SE-601 76 Norrkoping, Sweden (1999), p. 56

37. J. Raisanen, R. Joelsson, Tellus 53A, 547 (2001)

38. M. Rummukainen, et al., Nordic Hydrol. 34, 399 (2003)

39. M. Beniston, F. Keller, B. Koffi, S. Goyette, Theor. Appl. Clim. 76, 125 (2003)

40. J.H. Christensen, O.B. Christensen, Nature 421, 805 (2003)

41. O.B. Christensen, J.H. Christensen, Global Planet. Change 44, 107 (2004)

42. E. Kjellstrom, Ambio 33, 193 (2004) 
43. T. Semmler, D. Jacob, Global Planet. Change 44, 119 (2004)

44. E. Sanchez, C. Gallardo, M.A. Gaertner, A. Arribas, M. de Castro, Global Planet. Change 44, 163 (2004)

45. J.S. Pal, F. Giorgi, X. Bi, Geophys. Res. Lett. 31, L13202 (2004)

46. C. Schar, et al., Nature 427, 332 (2004)

47. F. Giorgi, X. Bi, J.S. Pal, Clim. Dyn. 23, 839 (2004)

48. J. Raisanen, et al., Clim. Dyn. 22, 13 (2004)

49. M. Ekstrom, H.J. Fowler, C.G. Kislby, P.D. Jones, J. Hydrol. 300, 234 (2005)

50. M. Deque, et al., Clim. Dyn. 25, 653 (2005)

51. X.J. Gao, J.S. Pal, F. Giorgi, Geophys. Res. Lett. 33, L03706 (2006)

52. N.S. Diffenbaugh, J.S. Pal, X.J. Gao, F. Giorgi, Geophys. Res. Lett. 34, L11706 (2007)

53. J.H. Christensen, O.B. Christensen, Clim. Change 81, 7 (2007)

54. D. Jacob, et al, Clim. Change 81, 31 (2007)

55. M. Deque, et al., Clim. Change 81, 53 (2007)

56. M. Beniston, et al., Clim. Change 81, 71 (2007)

57. A.A.D. Van Ulden, G. Lenderink, B. Van Den Hurk, E. Van Meijgaard, Clim. Change 81, 179 (2007)

58. P.L. Vidale, D. Luthi, R. Wegmann, C. Schar, Clim. Change 81, 209 (2007)

59. G. Lenderink, A. van Ulden, E. van den Hurk, E. van Meijgaard, Clim. Change 81, 233 (2007)

60. E. Kjellstrom, et al., Clim. Change 81, 249 (2007)

61. B. Rockel, K. Woth, Clim. Change 81, 267 (2007)

62. M. De Castro, C. Gallardo, K. Jylha, H. Tuomenvirta, Clim. Change 81, 329 (2007)

63. M.G. New, M. Hulme, P.D. Jones, J. Clim. 13, 2217 (2000)

64. T.D. Mitchel, Clim. Change 60, 217 (2003)

65. F. Giorgi, J. Clim. 21, 1589 (2008)

66. L. Terray, et al., J. Clim. 17, 4630 (2004)

67. E. Coppola, F. Kucharski, F. Giorgi, F. Molteni, Geophys. Res. Lett. 32, L23709 (2005)

68. F. Giorgi, Meteorol. Atmos. Phys. 89, 1 (2005) 